\title{
Lixiviação de aldicarbe em macrolisímetros de dois Latossolos
}

\author{
Nélio Ricardo Amaral Castro ${ }^{(1)}$, Renê Luís de Oliveira Rigitano(1), José Maria de Lima ${ }^{(2)}$ e Cristiane Jorge Bastos $^{(3)}$ \\ (1)Universidade Federal de Lavras (Ufla), Dep. de Entomologia, Caixa Postal 37, CEP 37200-000 Lavras, MG. E-mail: nelio_castro@yahoo.com.br, \\ rigitano@ufla.br (2)Ufla, Dep. de Ciência do Solo.E-mail: jmlima@ufla.br(3)Ufla, Dep.de Química. E-mail: cris.bastos@ufla.br
}

\begin{abstract}
Resumo - O objetivo deste trabalho foi avaliar a lixiviação do inseticida aldicarbe em macrolisímetros contendo material indeformado dos solos Latossolo Vermelho distroférrico (LVdf) e Latossolo Vermelho-Amarelo distrófico (LVAd), em condições de campo. Uma formulação granulada de aldicarbe foi aplicada na dose recomendada, a $5 \mathrm{~cm}$ de profundidade, em lisímetros de 1,0 m de diâmetro e 0,45 e 0,90 m de profundidade, no início do período chuvoso. Nos cinco meses seguintes, o volume de água percolada nos lisímetros foi medido e amostras de água foram analisadas por cromatografia gás-líquido para a determinação da concentração de resíduos do composto. Os resíduos de aldicarbe e de seus produtos de oxidação ativos, sulfóxido e sulfona de aldicarbe, foram conjuntamente determinados na forma de sulfona de aldicarbe. Houve alta mobilidade dos resíduos de aldicarbe nos solos, porém, a intensa degradação desses resíduos resultou em sua lixiviação em quantidades relativamente baixas, a profundidades abaixo de 0,45 m (4,9\% e 5,9\% no LVdf e LVAd, respectivamente); na água percolada nos lisímetros de 0,90 m foram detectados resíduos apenas no LVdf. O risco de contaminação do lençol freático nos solos estudados, caracterizados como muito profundos, é mínimo.
\end{abstract}

Termos para indexação: pesticida, contaminação, água do subsolo.

\section{Aldicarb leaching in macrolysimeters of two Latosols}

\begin{abstract}
The objective of this work was to evaluate the leaching of aldicarb in macrolysimeters containing undisturbed soil material of a distroferric Red Latosol and of a distrofic Red Yellow Latosol, under field conditions. A granular formulation of the aldicarb pesticide was applied at the recommended rate, at $5 \mathrm{~cm}$ depth, in soil columns of $1.0 \mathrm{~m}$ diameter by 0.45 and $0.90 \mathrm{~m}$ long, at the beginning of the rainy season. The volume of percolated water in each lysimeter was measured during the subsequent five months, and water samples were analysed by gas-liquid chromatography for the determination of the pesticide residues concentration. Residues of aldicarb and its toxic transformation products, aldicarb sulfoxide and aldicarb sulfone, were jointly determined as aldicarbe sulfone. There was high mobility of aldicarb residues in soils, although their fairly rapid degradation in the soil resulted in the leaching of relatively low amounts below the depth of $0.45 \mathrm{~m}$ ( $4.9 \%$ for the distroferric Red Latosol and 5.9\% for the distrofic Red Yellow Latosol). In 0.90 m lysimeters, aldicarb residues were detected only in the percolated water of the distroferric Red Latosol. Groundwater contamination risk in these soils, pointed out as too deep, is remote.
\end{abstract}

Index terms: pesticide, contamination, groundwater.

\section{Introdução}

O emprego de pesticidas tornou-se essencial nos sistemas atuais de produção agrícola, porém, a contrapartida do aumento de produtividade proporcionado pelo seu uso pode ser observada nos impactos ambientais. Esses impactos ambientais são decorrentes da toxicidade dos pesticidas aos organismos não-alvo e da contaminação do solo e dos recursos hídricos (Edwards, 1993; Hill, 1995).

O inseticida-nematicida aldicarbe vem sendo amplamente empregado no Brasil nas culturas do cafeeiro, citros e batata, e é comercializado em formulação granulada para aplicação no solo. Trata-se de um composto extremamente tóxico a mamíferos, aves e peixes, com valor de dose letal $\left(\mathrm{DL}_{50}\right)$ em torno de $1,0 \mathrm{mg} \mathrm{kg}^{-1} \mathrm{de}$ peso corpóreo em ratos brancos (Union Carbide Produtos Agropecuários, 1983).

Após a constatação da presença de resíduos desse composto em diversos poços e minas d'água nos Estados Unidos (Rothschild et al., 1982; Zake et al., 1982), vários estudos sobre a degradação e transporte do aldicarbe em solos têm sido realizados. Tais estudos revelaram que o aldicarbe é oxidado a sulfóxido e sulfona 
de aldicarbe, compostos tão tóxicos quanto o aldicarbe. Simultaneamente, ocorre a degradação do aldicarbe e seus produtos de oxidação, formando compostos nãocarbamatos (oximas e nitrilas), que, por sua vez, são pouco tóxicos (Bull et al., 1970; Andrawes et al., 1971; Lightfoot et al., 1987). Estudos sobre a meia-vida de degradação do aldicarbe em solos mostraram uma considerável variação nos resultados, com valores de meiavida de 10 dias a 36 meses, de acordo com a classe de solo, profundidade, umidade, temperatura e $\mathrm{pH}$ (Bromilow et al., 1980; Jones, 1987; Lightfoot et al., 1987; Barbosa \& Rigitano, 1994).

Sobre a lixiviação do aldicarbe e seus produtos de oxidação em solos, estudos revelaram alta mobilidade desses compostos em solos, especialmente de sulfóxido e sulfona de aldicarbe (Bromilow \& Leistra, 1980; Jones et al., 1986; Jones, 1987). A alta mobilidade desses últimos foi atribuída à sua baixa lipofilicidade (valores de $\log \mathrm{K}_{\mathrm{ow}}$ em torno de -0,6) e, conseqüentemente, ao baixo coeficiente de adsorção na matéria orgânica do solo (Leistra et al., 1976; Bromilow \& Leistra, 1980; Jones et al., 1986; Jones, 1987).

A quantidade de resíduos de aldicarbe lixiviada a certa profundidade em determinado solo depende principalmente das propriedades físico-químicas deste solo, da precipitação pluvial e da degradação dos resíduos no solo. Em áreas caracterizadas por solos rasos, arenosos, ácidos, temperaturas baixas e chuvas intensas, a aplicação do aldicarbe pode resultar no transporte de resíduos até o lençol freático, e daí a poços e minas d’água, conforme observado em várias regiões dos Estados Unidos, o que resultou na proibição do uso do aldicarbe em alguns estados daquele país (Zake et al., 1982; Jones, 1987).

O objetivo deste trabalho foi avaliar a lixiviação do inseticida aldicarbe em macrolisímetros contendo material indeformado dos solos Latossolo Vermelho distroférrico (LVdf) e Latossolo Vermelho-Amarelo distrófico (LVAd), em condições de campo.

\section{Material e Métodos}

A lixiviação do aldicarbe foi investigada em macrolisímetros do Departamento de Ciência do Solo da Universidade Federal de Lavras (Ufla), Lavras, MG. Foram utilizadas colunas contendo material de solo das classes Latossolo Vermelho distroférrico (LVdf) e Latossolo Vermelho-Amarelo distrófico (LVAd). As colunas de solo foram obtidas em 1983, de solos localizados no campus da Ufla, conforme Souza (1983). As colunas de solos foram coletadas em cilindros de aço de 1,0 m de diâmetro com 0,45 e 0,90 m de profundidade, mantendo-se a estrutura original dos solos. Algumas das propriedades físico-químicas dos solos estudados foram determinadas por ocasião da coleta das unidades de solo (Tabela 1).

A aplicação do pesticida foi feita no início do período chuvoso na região de Lavras, MG, em 3 de novembro de 2000. Foi utilizado o produto comercial Temik 150 (150 g de aldicarbe $\mathrm{kg}^{-1}$ ), que é formulado em grânulos para a aplicação no solo. Em cada coluna foram aplicados $14 \mathrm{~g}$ da formulação, quantidade estabelecida com base nas recomendações feitas pelos fabricantes para cafeeiros adultos, assumindo-se a área do lisímetro equivalente à uma cova de cafeeiro. $\mathrm{O}$ produto foi aplicado simulando-se uma aplicação com matraca, tendo sido incorporado a $5 \mathrm{~cm}$ de profundidade, em sete pontos $\left(2\right.$ g ponto $\left.^{-1}\right)$. Devido a restrições impostas pelo número de lisímetros disponíveis, em cada solo foram conduzidas duas repetições para a profundidade de $0,45 \mathrm{~m}$ e três repetições para a profundidade de $0,90 \mathrm{~m}$. O solo nas colunas foi mantido sem vegetação durante todo o experimento.

A água percolada nos lisímetros foi coletada em recipientes de aço inox, com $15 \mathrm{~L}$ de capacidade, acoplados à tubulação proveniente dos lisímetros. Por ocasião das coletas, o volume de água percolada foi medido e uma amostra $(500 \mathrm{~mL})$ foi separada para análise. Foram analisadas amostras coletadas até o final do período

Tabela 1. Características físico-químicas dos solos estudados, de acordo com Souza (1983).

\begin{tabular}{|c|c|c|c|c|c|c|c|c|}
\hline \multirow[t]{2}{*}{ Solo $^{(1)}$} & \multirow{2}{*}{$\begin{array}{l}\text { Profundidade } \\
(\mathrm{cm})\end{array}$} & \multicolumn{3}{|c|}{ Análise granulométrica $\left(\mathrm{g} \mathrm{kg}^{-1}\right)$} & \multirow{2}{*}{$\begin{array}{r}\mathrm{MO}^{(2)} \\
\left(\mathrm{g} \mathrm{kg}^{-1}\right) \\
\end{array}$} & \multirow{2}{*}{$\begin{array}{c}\mathrm{Fe}_{2} \mathrm{O}_{3}^{(3)} \\
\left(\mathrm{g} \mathrm{kg}^{-1}\right) \\
\end{array}$} & \multicolumn{2}{|c|}{$\mathrm{pH}$} \\
\hline & & Areia & Silte & Argila & & & $\mathrm{H}_{2} \mathrm{O}$ & $\mathrm{KCl} 1 \mathrm{M}$ \\
\hline \multirow[t]{3}{*}{ LVdf } & $0-8$ & 90 & 240 & 670 & 42 & 263 & 5,2 & 5,7 \\
\hline & $8-52$ & 80 & 240 & 680 & 13 & 286 & 5,0 & 5,2 \\
\hline & $52-100$ & 80 & 200 & 720 & 11 & 288 & 5,9 & 5,3 \\
\hline \multirow[t]{3}{*}{ LVAd } & $0-40$ & 360 & 50 & 590 & 32 & 82 & 4,2 & 5,3 \\
\hline & $40-70$ & 260 & 30 & 710 & 11 & 98 & 4,2 & 5,1 \\
\hline & 70-93 & 320 & 50 & 630 & 8 & 95 & 4,5 & 5,1 \\
\hline
\end{tabular}

(1)LVdf: Latossolo Vermelho distroférrico; LVAd: Latossolo Vermelho-Amarelo distrófico. ${ }^{(2)}$ Matéria orgânica do solo (MO) $=$ C x 1,724. ${ }^{(3)}$ Obtido pelo extrato sulfúrico. 
chuvoso, por volta de 150 dias após a aplicação. Aos 190 dias após a aplicação, procedeu-se a adição diária de 15 L de água a alguns lisímetros, durante três semanas; o volume de água percolada nesses lisímetros foi diariamente medido e, a intervalos de dois ou três dias, uma amostra foi coletada para análise de resíduos.

A determinação da concentração de aldicarbe nas amostras de água foi realizada segundo Piffer \& Rigitano (1991), mediante a qual o aldicarbe e seus produtos de oxidação tóxicos (sulfóxido e sulfona de aldicarbe) são conjuntamente determinados na forma de sulfona de aldicarbe. Separou-se uma subamostra de $100 \mathrm{~mL}$, que foi submetida à extração dos resíduos em funil de separação através de três partições sucessivas com $50 \mathrm{~mL}$ de diclorometano, passando-se às fases orgânicas em $20 \mathrm{~g}$ de sulfato de sódio anidro. Após eliminação do diclorometano em rotavapor, os resíduos foram submetidos à oxidação, em $2 \mathrm{~mL}$ de solução de ácido peracético a $2 \%$ em acetato de etila, durante três horas. O ácido peracético foi eliminado através de fluxo de ar proveniente de bomba pneumática, e os resíduos transferidos em acetona para tubos de centrífuga com volume final de $2 \mathrm{~mL}$.

Na determinação quantitativa dos resíduos, utilizouse um cromatógrafo a gás, modelo CG-370, operando com detector fotométrico de chama e filtro de enxofre (394 nm). Utilizou-se uma coluna do tipo empacotada de vidro (1,80 m de comprimento e $2 \mathrm{~mm}$ de diâmetro interno), contendo 5\% SP-1000 em supelcoport 100/120. Os fluxos do gás de arraste $\left(\mathrm{N}_{2}\right)$ e dos gases da chama ( $\mathrm{H}_{2}$ e ar sintético) foram 52, 170 e $240 \mathrm{~mL} \mathrm{~min}^{-1}$, respectivamente. As temperaturas utilizadas no vaporizador, coluna e detector foram $240^{\circ} \mathrm{C}, 236^{\circ} \mathrm{C}$ e $240^{\circ} \mathrm{C}$, respectivamente. Nessas condições, o tempo de retenção do sulfona de aldicarbe foi de 2 minutos e 31 segundos. A quantificação do sulfona de aldicarbe foi realizada pela comparação das alturas dos picos nas amostras com a curva de calibração, a qual foi obtida injetando-se 2 a $50 \mathrm{ng}$, mantidos os volumes de injeção em $2 \mu \mathrm{L}$. O padrão analítico utilizado foi obtido junto à Agência de Proteção Ambiental dos Estados Unidos, tendo especificação de pureza acima de $99 \%$. Na certificação da eficiência do método analítico, foram realizadas análises de amostras de água fortificadas com aldicarbe, sulfóxido e sulfona de aldicarbe, nas concentrações 0,05 , 0,5 e 5,0 $\mathrm{mg} \mathrm{L}^{-1}$ dos três compostos.

$\mathrm{Na}$ estimativa da quantidade total de resíduos percolados em cada coluna, calculou-se inicialmente a quantidade percolada em cada coleta de água, com base na concentração de resíduos na subamostra $(100 \mathrm{~mL})$ analisada e no volume de água da respectiva coleta. Por causa do grande número de amostras geradas e das limitações de infra-estrutura laboratorial, nem todas as coletas de água tiveram uma amostra de $100 \mathrm{~mL}$ separada para análise. A concentração dos resíduos nessas coletas foi estimada por meio do cálculo da média das concentrações encontradas nas coletas anteriores e posteriores. A quantidade total de resíduos percolados em cada lisímetro pôde ser então estimada, e os resultados foram expressos em termos de porcentagem da quantidade aplicada de ingrediente ativo. Como os resíduos de aldicarbe foram determinados na forma de sulfona de aldicarbe, no cálculo dessa porcentagem levou-se em consideração a diferença entre os pesos moleculares do aldicarbe e do sulfona de aldicarbe.

Os dados diários de precipitação pluvial e temperatura média do ar, durante todo o período experimental, foram obtidos na Estação Meteorológica da Ufla, localizada a cerca de $40 \mathrm{~m}$ dos lisímetros.

\section{Resultados e Discussão}

Os resultados dos testes de recuperação do aldicarbe, sulfóxido de aldicarbe e sulfona de aldicarbe em amostras de água fortificadas com cada composto ficaram acima de 86\%, confirmando a eficiência do método analítico utilizado. Devido à falta de conhecimento sobre a proporção desses compostos nas amostras, os teores de resíduos encontrados não foram corrigidos de acordo com a porcentagem de recuperação. Com base nos cromatogramas obtidos nesses testes de recuperação, o limite mínimo de determinação dos resíduos de aldicarbe em amostras de água, pelo método utilizado, foi estimado em $0,01 \mathrm{mg} \mathrm{L}^{-1}$. Os dados climatológicos obtidos durante o período experimental foram arranjados de maneira semanal (Figura 1).

Nos dois solos estudados, foram encontrados resíduos de aldicarbe, já nas primeiras amostras de água percolada nos lisímetros de $0,45 \mathrm{~m}$, em concentrações muito maiores do que nas coletas subseqüentes (Figura 2). O termo resíduos de aldicarbe refere-se à soma do composto original e seus produtos de oxidação tóxicos (sulfóxido e sulfona de aldicarbe), os quais foram determinados conjuntamente.

A primeira coleta de água ocorreu no 11ํ dia após a aplicação em todos os lisímetros de 0,45 m, após o registro de uma chuva relativamente mais intensa (39,8 mm). Resíduos de aldicarbe foram encontrados 
nas amostras de água na primeira coleta, nos lisímetros de ambos os solos. Até o 19o dia após a aplicação, ocorreram três eventos adicionais de precipitação mais in-

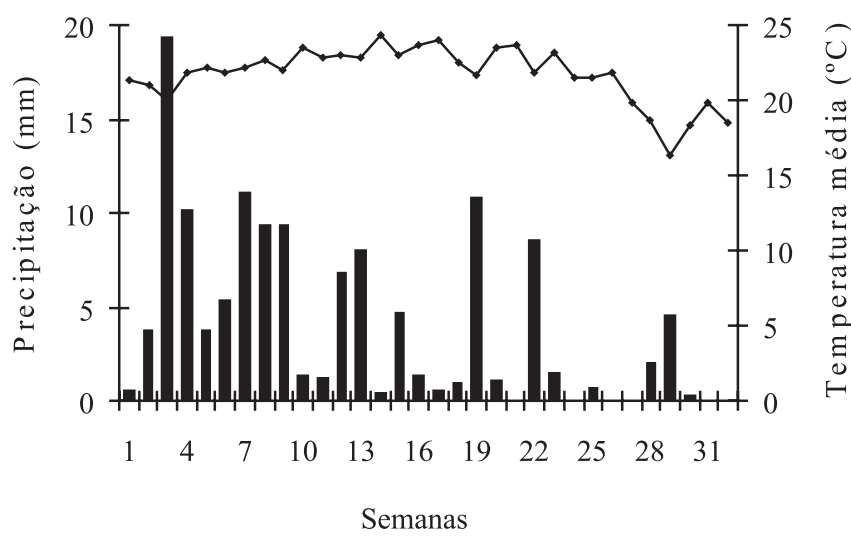

Figura 1. Precipitação e temperatura média diária, a cada semana, no período de 31/10/2000 a 11/6/2001.

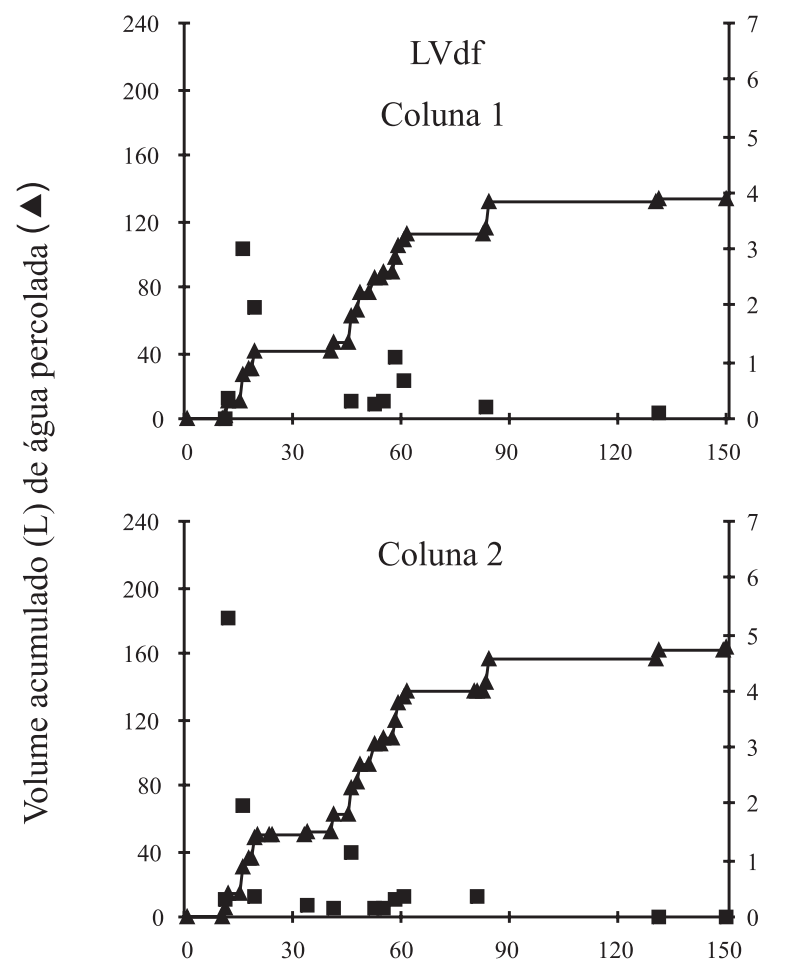

tensa (25,2, 56,2 e 60,2 mm aos 12, 16 e 19 dias, respectivamente), resultando na lixiviação, até essa data, de aproximadamente $90 \%$ da quantidade total de resíduos lixiviados abaixo de $0,45 \mathrm{~m}$, em todo o período chuvoso. Esses resultados indicaram que parte do aldicarbe aplicado nos lisímetros foi inicialmente lixiviada de forma mais rápida, numa condição de não-equilíbrio, ou seja, essa parte teria sido liberada dos grânulos após as primeiras chuvas, sendo subseqüentemente arrastada rapidamente, através dos macroporos dos solos; tal arraste teria sido rápido por causa do tempo insuficiente para a completa interação dos resíduos com os colóides do solo. A lixiviação dos resíduos de aldicarbe foi semelhante nos lisímetros de $0,45 \mathrm{~m}$ de cada solo, não sendo observadas diferenças marcantes entre os dois solos estudados.

A partir dos 130 dias desde a aplicação, não foram mais detectados resíduos nas amostras de água percolada, ou foram encontrados em concentrações muito baixas, indicando uma rápida degradação dos resíduos de aldicarbe. Tal degradação deve ter sido ex-
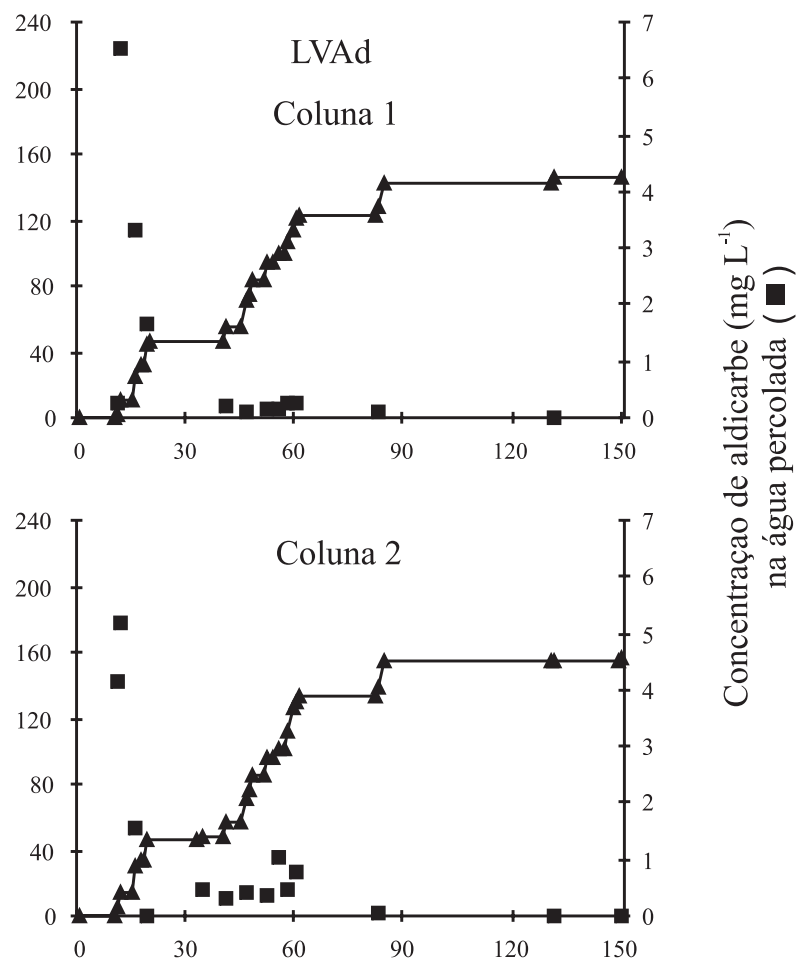

Dias após aplicação

Figura 2. Concentração de resíduos de aldicarbe na água percolada nos lisímetros de 0,45 m do Latossolo Vermelho distroférrico (LVdf) e do Latossolo Vermelho-Amarelo distrófico (LVAd). 
tremamente acentuada nos primeiros dez dias, quando o produto ainda encontrava-se mais próximo à superfície, com a temperatura máxima do ar chegando a $30^{\circ} \mathrm{C}$ em alguns dias e, certamente, acima deste patamar, na camada superficial do solo, onde a atividade microbiana também exerce maior ação sobre a degradação.

As quantidades totais estimadas de resíduos lixiviados nos lisímetros de 0,45 m de ambos os solos foram muito baixas em relação à dose aplicada de aldicarbe $(4,9 \%$ no LVdf e 5,9\% no LVAd). A adição de aproximadamente $15 \mathrm{~L}$ de água por dia, durante três semanas, em um dos lisímetros de cada solo, após o período de 190 dias da aplicação, não resultou na remoção de quantidades adicionais de resíduos. Tais resultados mostraram que a lixiviação dos resíduos de aldicarbe nos lisímetros de ambos os solos foi marcadamente restringida pela elevada taxa de degradação dos resíduos nos solos.

Piffer \& Rigitano (1991) investigaram a lixiviação de resíduos de aldicarbe em um Latossolo Vermelho distroférrico (Latossolo Roxo) da região de Lavras, MG, durante o período chuvoso, tendo estimado um transporte de resíduos em torno de $16 \%$ da dose aplicada, à profundidade abaixo de $0,50 \mathrm{~m}$. Esses autores também investigaram a lixiviação dos resíduos de aldicarbe em condições de campo, porém, foram usados tubos de PVC de apenas $5 \mathrm{~cm}$, os quais foram introduzidos nos solos. É possível que tal método tenha alterado mais a estrutura natural dos solos, em relação àquela utilizada neste trabalho, tendo proporcionado maior lixiviação dos resíduos de aldicarbe naquele estudo. Contudo, como a precipitação pluvial ocorrida no período de estudo desses autores foi muito maior do que aquela ocorrida no período deste trabalho, a menor lixiviação dos resíduos de aldicarbe observada é atribuída principalmente à menor precipitação pluviométrica. Piffer \& Rigitano (1991) estimaram valores de meia-vida de degradação dos resíduos de aldicarbe naqueles solos em torno de 20 dias, corroborando a assertiva anterior de que a rápida degradação dos resíduos é um fator limitante à sua lixiviação.

Os resultados obtidos nas análises de água coletada nos lisímetros de 0,90 m revelaram diferença marcante entre os dois solos (Figura 3). Nas colunas do LVdf foram detectados resíduos de aldicarbe em quase todas as amostras, enquanto nas colunas de LVAd não foram detectados resíduos em quaisquer das amostras coletadas durante os 150 dias após a aplicação, apesar de os padrões de eluição da água efetivamente obser- vados nos lisímetros não terem revelado diferenças marcantes entre os solos.

Os resultados obtidos nos lisímetros de 0,90 m mostraram maior lixiviação dos resíduos de aldicarbe no LVdf, o que pode ser atribuído a vários fatores. Briggs (1981) constatou que a sorção de compostos eletricamente neutros, como o aldicarbe, ocorre principalmente na matéria orgânica do solo, e o teor médio de matéria orgânica no LVAd (20\%) revelou-se maior do que no LVdf (1,5\%), valores esses referentes à média ponderada do teor de matéria orgânica até a profundidade de $0,90 \mathrm{~m}$, considerando-se os valores apresentados na Tabela 1. É possível que diferenças entre os solos, com relação à natureza da matéria orgânica, tenham resultado em diferenças no grau de sorção dos resíduos de aldicarbe. O solo LVdf apresenta níveis muito mais elevados de óxidos de ferro (Tabela 1), os quais, reconhecidamente, interagem com a matéria orgânica do solo, diminuindo as propriedades sortivas da mesma, com relação a moléculas orgânicas (Canellas et al., 1999). A maior lixiviação dos resíduos no LVdf, por sua vez, pode ser atribuída à menor taxa de degradação dos resíduos nesse solo, em relação ao LVAd. Barbosa \& Rigitano (1994) investigaram a taxa de degradação do aldicarbe em diferentes classes de solo da região de Lavras e constataram uma taxa de degradação mais de duas vezes menor em amostras do horizonte A de um LV do que em um LVA.

As quantidades totais estimadas de resíduos lixiviados nas colunas de $0,90 \mathrm{~m}$ do LVdf, em relação à quantidade aplicada de aldicarbe, foram próximas àquelas nas colunas de $0,45 \mathrm{~m}$, indicando que a taxa de degradação dos resíduos foi sensivelmente diminuída em profundidades abaixo de 0,45 m. Barbosa \& Rigitano (1994) constataram taxas de degradação do aldicarbe até quatro vezes menores em amostras do horizonte $\mathrm{C}$ em relação àquelas do horizonte $\mathrm{A}$, em diferentes solos. A adição diária de $15 \mathrm{~L}$ de água, durante três semanas, a um dos lisímetros de 0,90 m do LVdf, após o período de 150 dias da aplicação do aldicarbe, não resultou em remoção de quantidades adicionais de resíduos, confirmando que a degradação desses foi limitante à sua lixiviação.

Os resultados obtidos vêm confirmar o alto potencial de lixiviação dos resíduos de aldicarbe em solos, conforme constatado por outros autores em solos norteamericanos (Jones \& Back, 1984; Jones et al., 1986), europeus (Bromilow \& Leistra, 1980; Fava et al., 2001) e brasileiros (Piffer \& Rigitano, 1991; Scorza Junior et al., 
2000). Esse alto potencial de lixiviação tem sido atribuído à rápida oxidação do aldicarbe a sulfóxido e sulfona de aldicarbe em solos, e à baixa sorção desses na matéria orgânica do solo, em virtude de sua baixa lipofilicidade (valores de $\log \mathrm{K}_{\mathrm{ow}}$ iguais a 1,08, $-0,69$ e -0,57, para aldicarbe, sulfóxido e sulfona de aldicarbe, respectivamente).

A alta taxa de degradação dos resíduos de aldicarbe nos solos restringiu significativamente sua lixiviação,

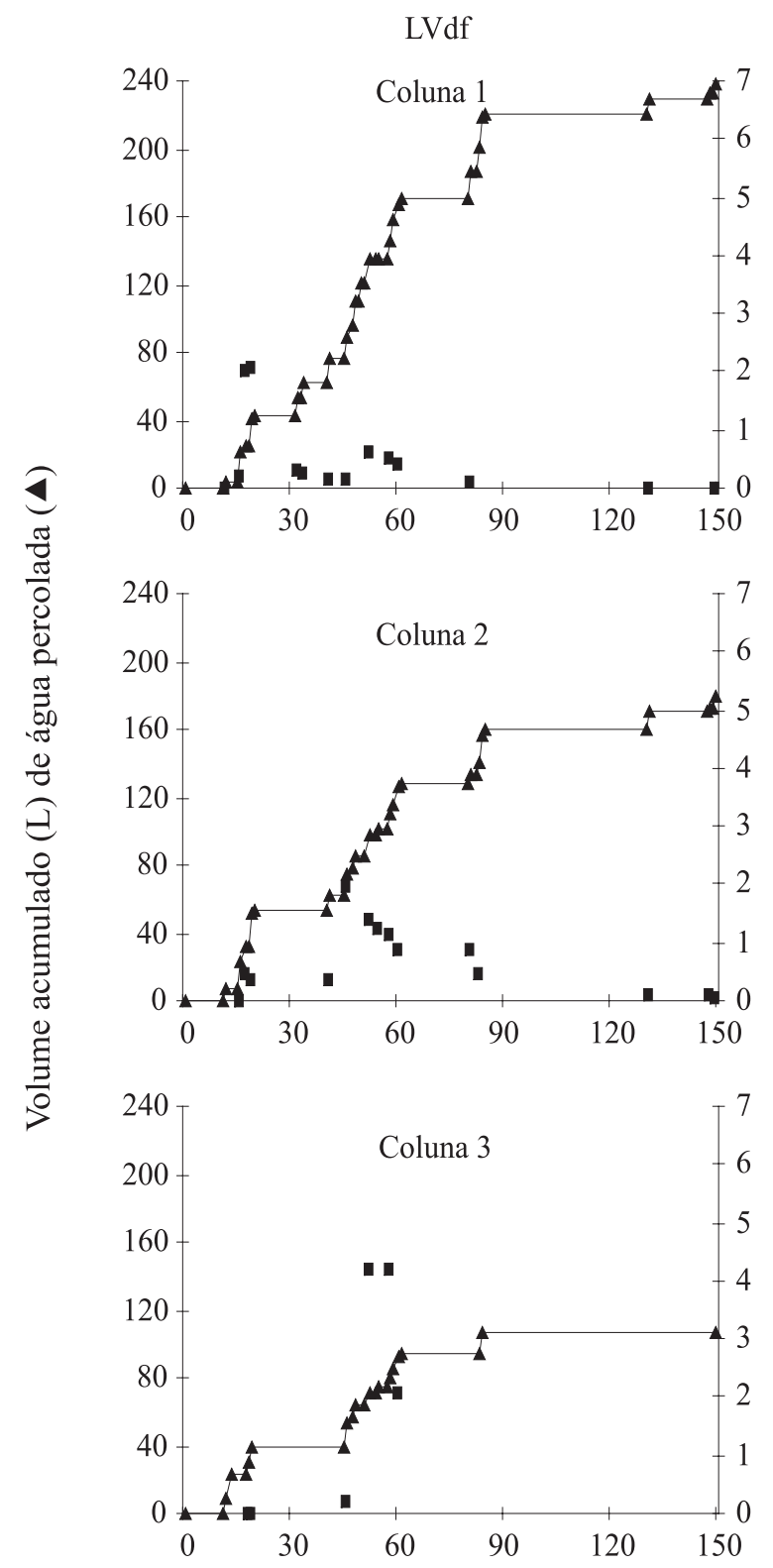

porém, conforme visto anteriormente, quantidades apreciáveis de resíduos (em torno de $5 \%$ da quantidade aplicada) foram lixiviadas a profundidades abaixo de $0,45 \mathrm{~m}$ em ambos os solos e abaixo de $0,90 \mathrm{~m}$ nas colunas do LVdf. Os solos estudados são tipicamente profundos, com o lençol freático localizado a vários metros de profundidade. Admitindo-se essa condição, os resultados permitem inferir que os riscos de contaminação do lençol freático nesses solos, com resíduos de aldicarbe pro-
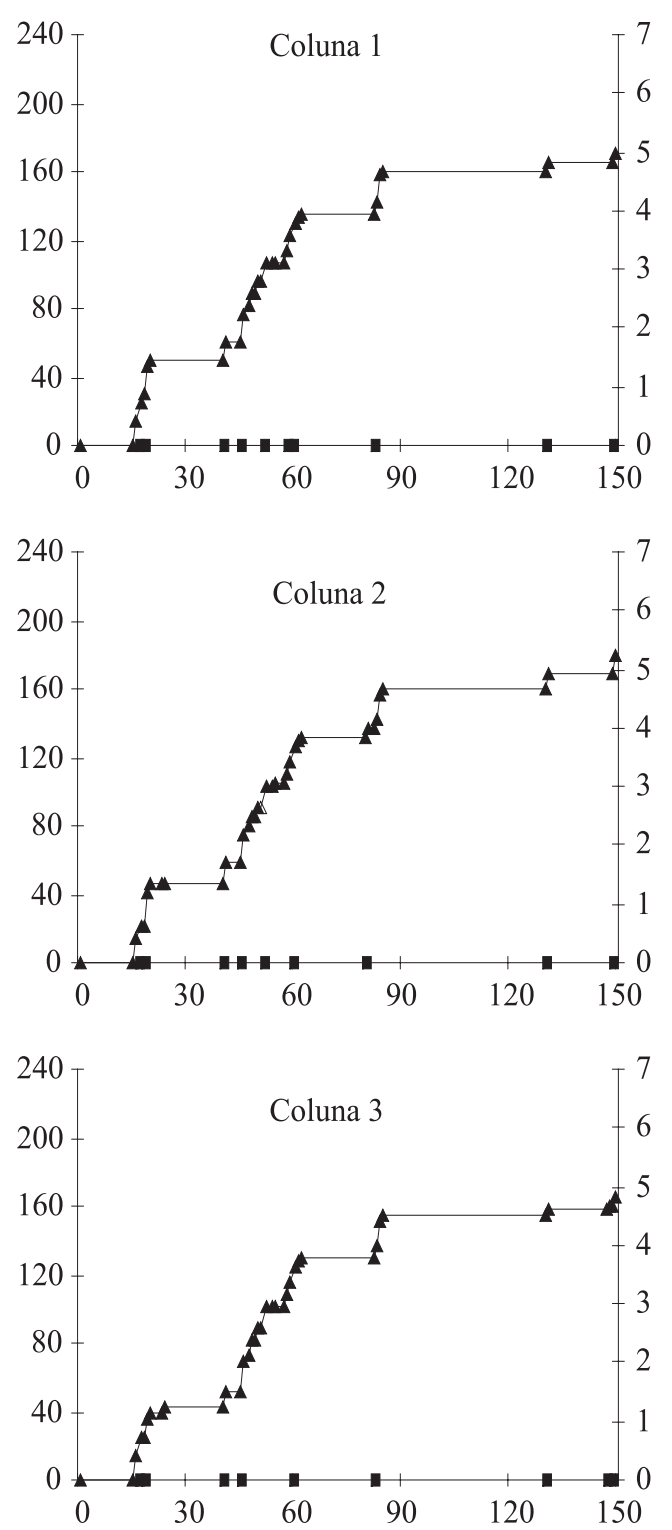

Dias após aplicação

Figura 3. Concentração de resíduos de aldicarbe na água percolada nos lisímetros de 0,90 m do Latossolo Vermelho distroférrico (LVdf) e do Latossolo Vermelho-Amarelo distrófico (LVAd). 
venientes da aplicação do produto de acordo com sua recomendação, seriam mínimos ou mesmo desprezíveis. Contudo, esses mesmos resultados, obtidos em condições próximas àquelas de campo, em função da utilização de lisímetros com grandes dimensões e com os solos de estrutura indeformada, confirma o risco de contaminação da água do lençol freático, e possivelmente de minas e poços de água, em solos com lençol freático próximo à superfície. De fato, resíduos de aldicarbe foram encontrados em poços e minas d'água dos EUA (Zake et al., 1982; Jones, 1987; Domagalski \& Dubrosvisky, 1992), principalmente em áreas caracterizadas por solos arenosos e pouco profundos.

Embora os resultados deste estudo reflitam condições específicas de solo e clima, tais resultados poderão ser utilizados na calibração e validação de modelos de simulação da lixiviação de pesticidas em solos brasileiros, permitindo assim a utilização desses modelos para a análise de risco de contaminação da água do subsolo nas condições de solo e clima brasileiros.

\section{Conclusões}

1.Em ambos os solos ocorre lixiviação de quantidades relativamente baixas de resíduos abaixo de 0,45 m de profundidade.

2. A lixiviação dos resíduos de aldicarbe é semelhante nos dois solos até $0,45 \mathrm{~m}$ de profundidade; nas colunas de 0,90 m, a lixiviação desses resíduos é mais pronunciada no Latossolo Vermelho distroférrico.

3. Os resíduos de aldicarbe apresentam alta mobilidade nos solos, porém, a intensa degradação desses resíduos é um fator limitante à sua lixiviação.

4. Os riscos de contaminação do lençol freático desses solos com resíduos de aldicarbe, em condições práticas de uso do composto, são mínimos ou desprezíveis.

\section{Agradecimento}

Ao CNPq, pelas bolsas concedidas aos autores Nélio Ricardo Amaral Castro e José Maria de Lima.

\section{Referências}

ANDRAWES, N.R.; BAGLEY, W.P.; HERRETT, R.A. Fate and carryover properties of Temik aldicarb pesticide [2-methyl-2(methylthio) propionaldehyde O-(methylcarbamoyl) oxime] in soil. Journal of Agricultural and Food Chemistry, v.19, p.727-730, 1971.
BARBOSA, T.M.L.; RIGITANO, R.L.O. Influência da classe e profundidade do solo na degradação do inseticida-nematicida aldicarbe. Pesquisa Agropecuária Brasileira, v.29, p.955-960, 1994.

BRIGGS, G.G. Theoretical and experimental relationship between soil adsorption, octanol-water partition coefficients, water solubilities, bioconcentration factors, and the parachlor. Journal of Agriculture and Food Chemistry, v.29, p.1050-1059, 1981.

BROMILOW, R.H.; BAKER, J.J.; FREEMAN, M.A.; GOROG, $\mathrm{K}$. The degradation of aldicarb and oxamyl in soil. Pesticide Science, v.11, p.371-378, 1980.

BROMILOW, R.H.; LEISTRA, M. Measured and simulated behaviour of aldicarb and its oxidation products in fallow soils. Pesticide Science, v.1, p.389-395, 1980.

BULL, D.D.; STOKES, R.A.; COPPEDGE, J.R.; RIDGWAY, R.L. Further studies of the fate of aldicarb in soil. Journal of Economic Entomology, v.63, p.1283-1289, 1970.

CANELLAS, L.P.; SANTOS, G.A.; AMARAL SOBRINHO, N.M.B. Reações da matéria orgânica. In: SANTOS, G.A.; CAMARGO, F.A.O. (Ed.). Fundamentos da matéria orgânica do solo. Curitiba: Gênesis, 1999. p.69-86.

DOMAGALSKI, J.L.; DUBROVSKY, N.M. Pesticide residues in ground water of the San Joaquim Valley, California. Journal of Hydrology, v.130, p.299-338, 1992.

EDWARDS, C.A. The impact of pesticides on the environment. In: PIMENTEL, D.; LEHMAN, H. (Ed.). The pesticide question: environment, economics and ethics. New York: Chapman \& Hall, 1993. p.13-46.

FAVA, L.; BOTTONI, P.; CROBE, A.; CARACCIOLO, A.B.; FUNARI, E. Assessment of leaching potential of aldicarb and its metabolites using laboratory studies. Pest Management Science, v.57, p.1135-1141, 2001.

HILL, E.F. Organophosphorus and carbamate pesticides. In: HOFFMAN, D.J.; RATTNER, B.A.; BURTON JUNIOR, G.A.; CAIRNS JUNIOR, J. (Ed.). Handbook of ecotoxicology. London: Lewis Publishers, 1995. p.243-273.

JONES, R.L. The aldicarb experience: 2- Results of monitoring and research programs. Triangle Park, NC: Union Carbide Agricultural Products Company, 1987. 46p.

JONES, R.L.; BACK, R.C. Monitoring aldicarb residues in Florida soil and water. Environmental Toxicology and Chemistry, v.3, p.9-20, 1984.

JONES, R.L.; BLACK, G.W.; ESTES, T.L. Comparison of computer predictions with unsatured zone field data for aldicarb and aldoxycarb. Environmental Toxicology and Chemistry, v.5, p.1027-1037, 1986.

LEISTRA, M.; SMELT, J.H.; LEXMOND, T.M. Conversion and leaching of aldicarb in soil columns. Pesticide Science, v.7, p.471482, 1976.

LIGHTFOOT, E.N.; THORNE, P.S.; JONES, R.L.; HANSEN, J.L.; ROMINE, R.R. Laboratory studies on mechanisms for the degradation of aldicarb, aldicarb sulphoxide and aldicarb sulphone. Environmental Toxicology and Chemistry, v.6, p.377-394, 1987.

PIFFER, R.; RIGITANO, R.L.O. Lixiviação e degradação do inseticida aldicarbe em dois diferentes solos. Ciência e Prática, v.15, p.355-363, 1991. 
ROTHSCHILD, E.R.; MANSER, R.J.; ANDERSON, M.P. Investigation of aldicarb in groundwater in selected areas in the central sand plains of Wisconsin. Ground Water, v.4, p.437-445, 1982.

SCORZA JÚNIOR, R.P.; RIGITANO, R.L.O.; LIMA, L.A.; GOUVÊA, A.V. Avaliação de dois simuladores para predição da lixiviação de sulfona de aldicarbe em um Latossolo Vermelho-Amarelo. Pesquisa Agropecuária Brasileira, v.35, p.241-250, 2000.

SOUZA, J.J. de. Complemento de uma bateria de lisímetros: coleta dos solos e implantação do complexo. In: ESCOLA SUPERIOR DE
AGRICULTURA DE LAVRAS. Materiais corretivos: relatório final. Lavras, 1983. p.171-198.

UNION CARBIDE PRODUTOS AGROPECUÁRIOS. Temik defensivo agrícola aldicarbe: uma avaliação científica. São Paulo: Union Carbide do Brasil, 1983. 63p.

ZAKE, M.H.; MORAN, D.; HARRIS, D. Pesticide in groundwater: the aldicarb story in Suffolk County. American Journal of Public Health, v.72, p.1319-1395, 1982.

Recebido em 29 de setembro de 2004 e aprovado em 10 de fevereiro de 2005 